\title{
Manifesto Ocupação 'A favela ocupa o Abrascão 2018: saúde é democracia, mas qual democracia vivemos na favela?'
}

\author{
Manifest Occupation 'The favela occupies Abrascão 2018: health is \\ democracy, but which democracy do we experience in the favela?'
}

Mariana Lima Nogueira ${ }^{1}$, Maria das Mercês Navarro Vasconcellos ${ }^{2}$, Anastácia Ferreira dos Santos $\mathbf{3}$, Fábio Monteiro Falcão ${ }^{\mathbf{3}}$, Jorge Antônio dos Santos Nadais $\mathbf{2 , \mathbf { 3 }}$, Alex da Costa Pessoa ${ }^{\mathbf{3}}$, José Beserra de Araújo ${ }^{4}$

DOI: 10.1590/0103-11042019S827
1 Fundação Oswaldo Cruz (Fiocruz), Escola Politécnica de Saúde Joaquim Venâncio (EPSJV)

- Rio de Janeiro (RJ), Brasil. mariana.nogueira@fiocruz.br

2 Fundação Oswaldo Cruz (Fiocruz), Escola Naciona de Saúde Pública Sergio Arouca (Ensp) - Rio de Janeiro (RJ), Brasil.

${ }^{3}$ Comissão dos Agentes Comunitários de Saúde de Manguinhos (Comacs) Rio de Janeiro (RJ), Brasil.

${ }^{4}$ Movimento das Comunidades Populares (MCP) - Rio de Janeiro

(RJ), Brasil.
O PRESENTE TEXTO EXPRESSA UMA VOZ COLETIVA composta por moradores, trabalhadores e estudantes do complexo de favelas de Manguinhos, na cidade do Rio de Janeiro, que construíram um ato político, ocupação, denominado 'A favela ocupa o Abrascão!'. Esse evento aconteceu no campus da Fundação Oswaldo Cruz (Fiocruz), em Manguinhos, no dia 28 de julho de 2018, durante o XII Congresso Brasileiro de Saúde Coletiva (Abrascão), evento cujo tema central anunciado foi: Fortalecer o Sistema Único de Saúde (SUS), os direitos e a democracia.

O manifesto foi construído por trabalhadores moradores de Manguinhos, trabalhadores da Estratégia Saúde da Família, professoras e pesquisadoras da Fiocruz, durante dois encontros que aconteceram no turno da noite, em Manguinhos. Estes foram mobilizados pelo temário do Congresso organizado pela Associação Brasileira de Saúde Coletiva (Abrasco). O manifesto foi impresso e distribuído nas favelas e durante o evento, e se concretizou em uma atividade de ocupação no Congresso, com café da manhã comunitário e uma roda de conversa, formada por mais de cem pessoas entre congressistas, moradores e trabalhadores de Manguinhos e de outras favelas. A atividade incluiu a exibição do documentário 'Manguinhos resiste a mais uma enchente', feito pela Comissão de Agentes Comunitários de Manguinhos (Comacs) que abordou a grave enchente que aconteceu na região no dia 15 de fevereiro de 2018. 
Figura 1. Ocupação: a favela ocupa o Abrascão 2018

(A)

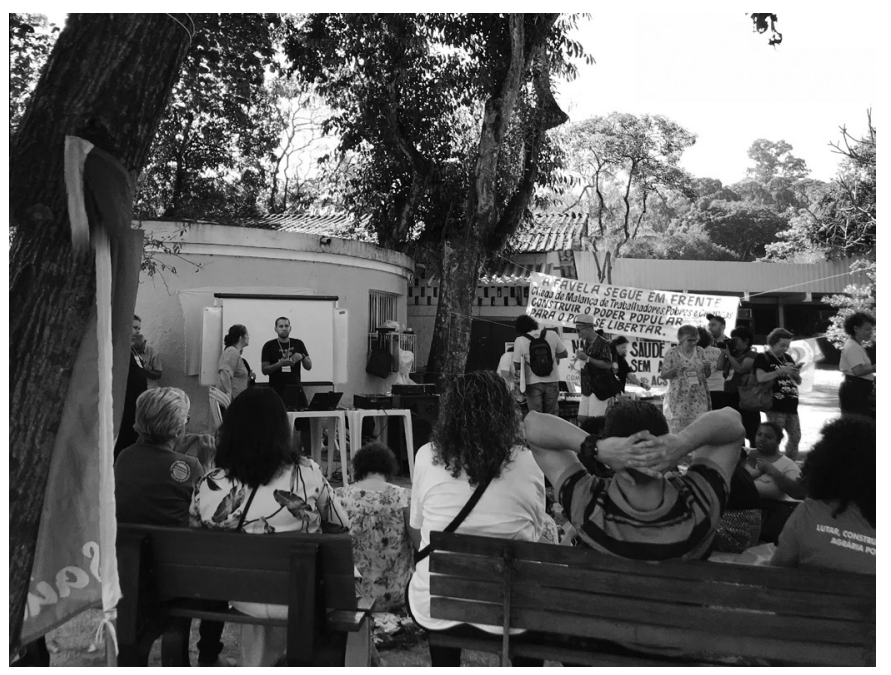

(B)

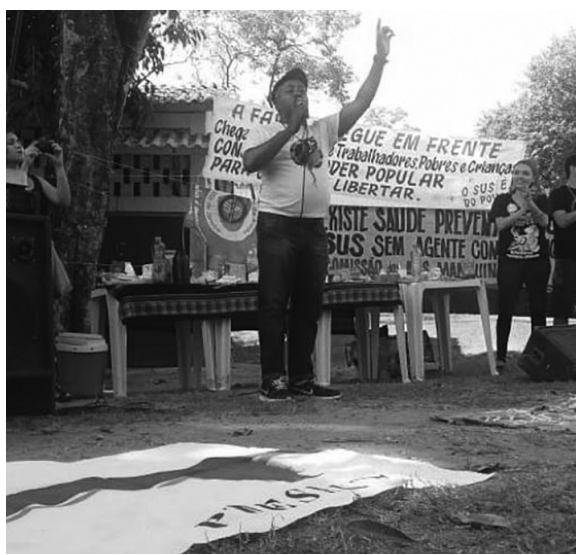

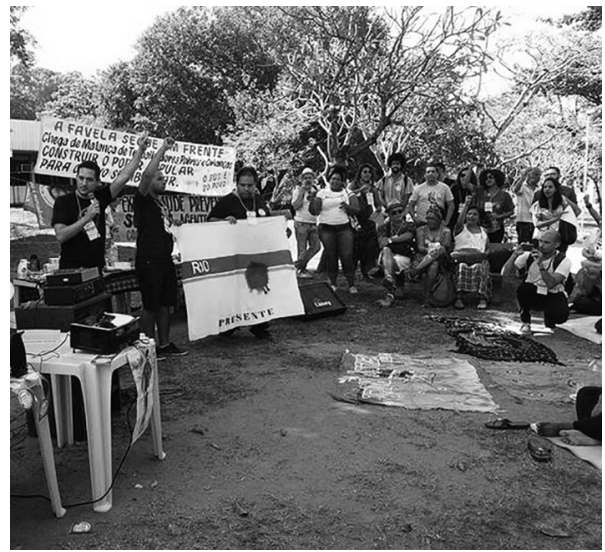

\section{Manifesto ocupação: a favela ocupa o Abrascão 2018!}

Saúde é democracia, mas qual democracia vivemos na favela? Qual democracia e para quem? Como pensar um evento de saúde coletiva, discussões sobre a favela e sobre violência sem a favela? A determinação social do processo saúde-doença em Manguinhos é marcada historicamente por uma perversa 'democracia' que, em uma sociedade de classes, no capitalismo, manifesta-se de maneira desigual e perversa nos territórios favelados em relação aos territórios onde se concentram as classes dominantes. Para ousarmos discutir que saúde é democracia, não podemos nos limitar às discussões sobre a participação política somente pela via institucional, mas, sim, precisamos romper com uma perspectiva restrita que naturaliza a democracia como um valor garantido em constituinte, e a afirme como processo que só será assegurado a partir da participação popular, da luta coletiva com a finalidade da extinção da sociedade 
de classes. Historicamente, o surgimento de um discurso legal que transforma o espaço da favela em um local de exceção possui o efeito de dizer a verdade de uma situação, assim como o de 'transformar' os moradores da favela em criminosos de alta periculosidade. É crucial reconhecermos que, no capitalismo, o Estado e suas formas jurídicas têm administrado o monopólio da regra e de suas exceções. Entender a formação histórica das favelas significa compreender esses espaços como resultados de um processo histórico marcado pela luta de classes, por discriminações, racismos, baixos salários, falta de ofertas de políticas públicas urbanas, de habitação, de saneamento para uma parte cada vez mais crescente da população segregada e marginalizada socioeconomicamente. As lógicas de ocupação que marcaram a história das favelas no Rio de Janeiro - e em diversas cidades do país e da América Latina - normalmente desembocam em condições socioambientais de 'risco'. Algumas se agravam diante das chuvas e da precariedade das habitações, como os desmoronamentos nos morros e as enchentes. Além disso, a presença do Estado por meio do seu aparelho coercitivo policial, unida à violência retratada no discurso das manchetes dos meios de comunicação que expõe para a sociedade os confrontos armados, a relação com a contravenção, os índices estatísticos que apontam para o aumento da violência, baseado nas operações policiais de repressão ao crime organizado, tornam historicamente a favela um local de terror e de medo. É uma violência histórica simbólica, cotidiana e institucionalizada. É a violência da exclusão. A democracia que queremos é aquela que será ratificada no processo de construção cotidiana pela classe trabalhadora, que não se limitará aos discursos. A favela não pode continuar do outro lado da janela da academia! Por uma democracia efetivamente justa, pela união dos trabalhadores na luta popular e anticapitalista! A favela ocupa o Abrascão!

O manifesto foi lido na íntegra ao microfone no início da atividade após a fala de uma das organizadoras que apresentou a motivação, a justificativa, os objetivos, a organização e a programação da atividade. Sobre a participação de moradores da favela de Manguinhos no Abrascão 2018, cabe citar as observações feitas por uma líder comunitária, Patrícia Evangelista:

A participação de moradores de Manguinhos nas atividades do Abrascão foi restrita à participação de oito pessoas inscritas pelo Conselho Gestor Intersetorial de Manguinhos que atuaram na condição de público desse evento, além de três ou quatro moradores que foram convidados a participarem de mesas no evento. Foram convites feitos a esses indivíduos não pela condição dessas pessoas serem moradoras de Manguinhos e sim por outros motivos, como as suas inserções nas discussões sobre as temáticas que estavam sendo debatidas na mesa. Essa falta de participação coletiva da favela de Manguinhos na construção de atividades desse evento nos mostra que o conhecimento e o saber popular ainda não são valorizados. Esse abismo incomodou um grupo de moradores e trabalhadores de Manguinhos e levou à organização do 'Favela Ocupa Abrascão'. Considerei essa atividade uma excelente oportunidade para trazer para o Abrascão 2018 a possibilidade de uma aproximação com a realidade de Manguinhos, território que abrigou esse evento. Assim como outras favelas do Rio de Janeiro, os moradores têm muito a dizer sobre o tema desse congresso: 'Fortalecer o SUS, os Direitos e a Democracia'1.

De fato, os moradores das favelas têm muito a dizer, afinal de contas, vivem em um território que é constituído historicamente por violências produzidas pelo Estado capitalista, e têm clareza que a democracia nunca foi vivida plenamente pela classe trabalhadora, e, portanto, não se restringe ao sufrágio universal, a um valor e a socialização da participação.

O manifesto expressa uma síntese de questões cruciais para a Reforma Sanitária: 
a necessária centralidade da categoria classe social para pensar os processos de participação social, os limites desses processos quando se resumem a participações por dentro do Estado e as determinações sociais do processo saúde-doença; a relação entre o modo de produção como se organiza a sociedade, o caráter do Estado e suas formas de expressão com vistas a não naturalização do que se chama de democracia e saúde².

\section{Referências}

1. Evangelista P. Favela ocupa os espaços acadêmicos. 2018. [acesso em 2019 mar 2]. Disponível em: https:// www.abrasco.org.br/site/eventos/congresso-brasileiro-de-saude-coletiva/abrascao-em-manguinhos-favela-ocupa-os-espacos-academicos/36238/.

2. Martins C, Prado FC, Figueiredo IM, et al. "Estratégia Democrático-Popular" e um inventário da Esquerda

\section{Colaboradores}

Nogueira ML (0000-0003-1881-7601)*, Vasconcellos MMN (0000-0003-1180-0321)*, Santos AF (0000-0002-6823-5944)*, Falcão FM (0000-0002-4564-6353)*, Nadais JAS (0000-0002-4696-6607)*, Pessoa AC (00000002-6077-9111)* e Araújo JB (0000-00034176-1968)* colaboraram igualmente na elaboração do manuscrito.
Revolucionária. In: Iasi M, Figueiredo IM, Neves V, et al., organizadores. A estratégia democrático-popular: um inventário crítico. Marília: Lutas Anticapital, 2019, p. 25-55.

Recebido em 10/06/2019

Aprovado em 04/09/2019

Conflito de interesses: inexistente

Suporte financeiro: não houve 